EVIDENCE BASED PUBLIC HEALTH POLICY AND PRACTICE

\title{
User requirements and understanding of public health networks in England
}

D K Fahey, E R Carson, D G Cramp, J A Muir Gray

J Epidemiol Community Health 2003;57:938-944

See end of article for authors' affiliations

.....................

Correspondence to: Dr D Fahey, Public Health Department, 4th Floor, West Wing, Camden Primary Care Trust, St

Pancras Hospital, St

Pancras Way, London NW1 OPE, UK:

faheydaragh@

hotmail.com

Accepted for publication 8 April 2003

\begin{abstract}
Background: The movement of public health professionals from health authorities to primary care trusts has increased their isolation and dependence on public health networks for communication.

Methods: A cross sectional survey of 60 public health professionals working in England was performed to determine their understanding of the term "public health network" and to explore the functions that they would like these networks to perform. It also assessed their attitudes towards a national network and towards individual, local, and national web sites to support these networks.

Results: The most popular functions were the support of CPD/education, the identification of expertise and maximisation of scarce resources, information sharing, and efficient information/ $\mathrm{knowledge} \mathrm{manage-}$ ment. The local and national networks and their web sites should provide information on current projects of the network and searches to identify people, expertise, and reports.

Conclusion: Public health professionals have a similar but broader understanding of the term "public health network" than that of the government with greater emphasis on sharing of information. The network is more likely to be successful if its priorities are maximising scarce resources, identification of expertise, $\mathrm{CPD} /$ education, and knowledge management.
\end{abstract}

$\mathrm{S}$ ince the changes of Shifting The Balance Of Power ${ }^{2}$ (STBoP) public health professionals have found themselves isolated in various government buildings. There are concerns that public health's expertise is being spread too lightly, however, according to STBoP the public health network will tackle this problem. There is a need to clarify what is meant by the term "public health network" because even though there are many different types of networks that vary tremendously in the degree of formality, management, and functions the term is used as though it refers to one entity. Therefore when a speaker/writer uses this term the audience are often unsure if they are referring to a specific type of public health network, the government definition of a network, the faculty definition, or to some all encompassing term.

STBoP uses the terms "managed public health networks" and "public health networks" interchangeably. It defines the public health network as a "network within the area covered by the strategic health authority to ensure that specialist functions are available to primary care trusts (PCTs) where it is not effective or economic to provide them in each PCT". ${ }^{1}$ Its functions, ${ }^{2}$ are to "pool expertise and skills in specialist areas of public health which can then be available to all PCTs, to share good practice, manage public health knowledge and very importantly, act as a source of learning and professional development." The faculty of public health medicine (FPHM) document Developing Public Health in Primary Care Trusts-A Framework for Discussion, ${ }^{3}$ defines similar functions for the networks but also states that the public health network's objectives should include ensuring "public accountability for the public health function" and "deliver public health programmes which can be performance managed". These objectives contradict the STBoP statement of the purposes of the networks that states, "they will not be a vehicle for performance management of the public health function". So clearly there is some confusion about whether the term "public health network" means the same as a "managed public health network" and if it does should one consider the government definition or the faculty definition.
Defining the public health network is important but it is more important to identify its user requirements, as this will increase the chances of successful implementation. Public health networks are likely to have a considerable information and communication (ICT) component and there have been examples in the past where ICT has been unsuccessfully introduced into the health arena, ${ }^{4}$ because a decision of the needs of those "on the ground" was made by those at a board level without finding out exactly what the users wanted.

This study aimed to develop a consensus understanding of the term "public health network" and understand its support and functional requirements. Specifically our objectives were to:

- Define a consensus understanding of the term "public health network" and compare it with the government and FPHM definitions

- Assess whether public health professionals felt that communication over the network would be predominantly electronic

- Identify what functions public health professionals would most like the network to provide

- Assess the support for a national public health network

- Assess the desire for and functional requirements of supporting web sites at an individual, local, and national level

- Development recommendations as to what functions the network should focus on to ensure its success

\section{METHODOLOGY}

Of a total of 82 people invited 60 agreed to an in-person interview (appendix A, see journal web site http://www.jech. $\mathrm{com} /$ supplemental) to determine their user requirements and

Abbreviations: STBoP, Shiffing The Balance of Power; PCT, primary care trust; FPHM, Faculty of Public Health Medicine 


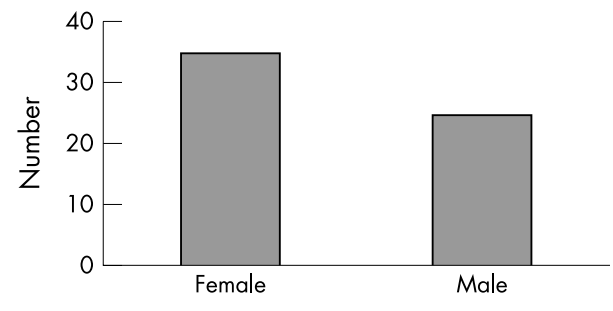

Figure 1 Sex of interviewees.

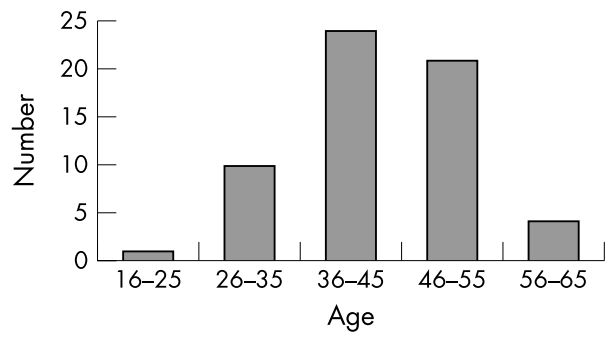

Figure 2 Age range of interviewees.

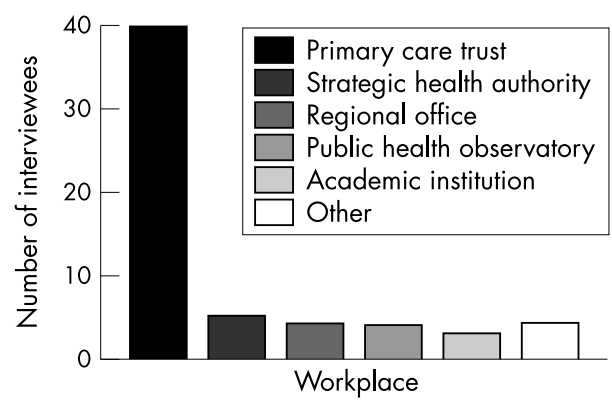

Figure 3 Workplace of interviewees.

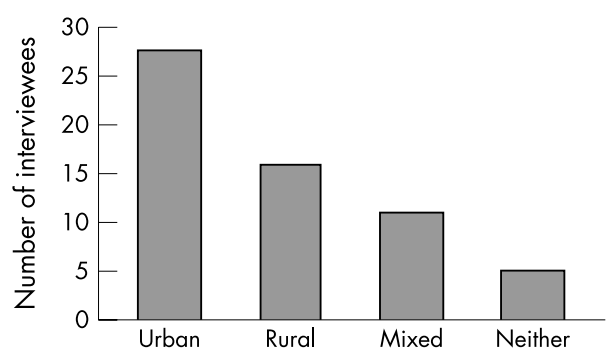

Figure 4 Urbanisation of area covered by interviewee.

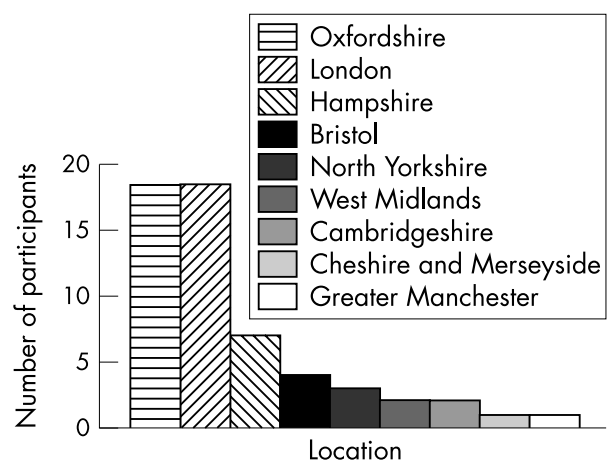

Figure 5 County covered by interviewee.
Table 1 Job title of those interviewed

\begin{tabular}{ll}
\hline Job title & Number \\
\hline Director of public health & 13 \\
Public health specialist & 8 \\
Consultant in public health & 7 \\
Information analyst & 7 \\
Health promotion specialist & 4 \\
Infection control nurse & 3 \\
Epidemiologist & 3 \\
Specialist registrar in public health & 3 \\
Network manager & 2 \\
Other & 10 \\
\hline
\end{tabular}

understanding of the term "public health network". All interviews were performed between June and August 2002. Those eligible to be interviewed included those who worked for at least 2.5 days a week in public health with public health work being defined as that which aimed to improve population health. The interviewees were not required to have any prior knowledge or membership of a public health network.

To accurately represent the probable members of a public health network sampling included public health professionals from a wide range of disciplines and from a wide range of organisations. Figures 1, 2, 3, 4, and 5 and table 1 show the sex, age group, work title and workplace of participants as well as the type of and location of population for whom they worked. Samples were taken from the north, east, west, and south of England although most interviewees were from Oxfordshire, Ealing, and Westminster PCTs. These organisations were selected to provide the majority of interviewees as they contained a reasonably stable workforce with most different specialties in public health represented and had both an urban and rural target population.

\section{The interview}

The interview was initially piloted on five public health professionals. Section A focused on the user understanding and desired functions of a public health network whereas section $\mathrm{B}$ examined user requirements for web sites given the scenario that there is a national network and a series of managed networks (as defined in STBoP, ${ }^{12}$ ). Question 11 (on the support for national public health networks) was added to the questionnaire at the halfway stage and was thus only answered by 22 interviewees.

Many questions required that the respondents ranked their responses to counter the bias introduced in the closed question that forces the interviewee to focus on alternatives that may not have occurred to them. Ideally the interviewees would have been asked to rank all their responses but it was felt this would lead to more irritation on the part of the interviewee and a prolonged interview time.

\section{Data analysis}

Questions 5, 6, 7, and 9 were analysed using Microsoft Excel's data analysis tool to produce the mean, standard deviation, and percentage. Question 9 was analysed by counting the number and percentage of times an option was selected. An answer of "it depends", "fifty-fifty" or don't know was included in the "other" option.

Answers to open questions were analysed using a coding system as described by Oppenhein. ${ }^{5}$ This entailed writing the full text of the answers and looking for common themes (question 8) and common functions (question 10). Appendix $\mathrm{B}$ gives the definitions of the themes and function identified (see journal web site http://www.jech.com/supplemental). Having identified the themes/functions the number of times 


\begin{tabular}{|c|c|c|}
\hline Question number & Topic & Answer \\
\hline \multicolumn{3}{|c|}{ Information on use of information technology } \\
\hline 4 & Hours on a computer per week & Mean: 25.27 (SD 10.73) \\
\hline & Understanding of the term "public health network" & Mean: 49.92 (SD 23.58) \\
\hline $\begin{array}{l}\text { Understanding of } \\
6\end{array}$ & $\begin{array}{l}\text { rm "public health network" } \\
\text { Percentage of interviewees with some } \\
\text { understanding of the term? }\end{array}$ & $96.66 \%(58 / 60)$ \\
\hline 8 & $\begin{array}{l}\text { Which of the following functions are provided } \\
\text { by a public health network? }\end{array}$ & \\
\hline 8.1 & $\begin{array}{l}\text { Link public health professionals within defined } \\
\text { geographical area? }\end{array}$ & $98.28 \%(57 / 58)$ \\
\hline a & Area within England & $22.82 \%(13 / 57)$ \\
\hline b & Throughout England & $5.26 \%(3 / 57)$ \\
\hline \multirow[t]{2}{*}{ c } & Both & $68.42 \%(39 / 57)$ \\
\hline & Other & $3.51 \%(2 / 57)$ \\
\hline \multirow{2}{*}{$\begin{array}{l}\text { (i) } \\
\text { (ii) }\end{array}$} & Predominantly* personal $†$ communication? & $7.02(4 / 57)$ \\
\hline & $\begin{array}{l}\text { Predominantly electronic communication? } \\
\text { Other }\end{array}$ & $\begin{array}{l}63.16(36 / 57) \\
29.82 \%(17 / 57)\end{array}$ \\
\hline 8.2 & $\begin{array}{l}\text { Link public health professionals with similar skills } \\
\text { and interests? }\end{array}$ & $87.93 \%(51 / 58)$ \\
\hline a & Area within England & $17.65 \%(9 / 51)$ \\
\hline b & Throughout England & $17.65 \%(9 / 51)$ \\
\hline c & Both & $60.78 \%(31 / 51)$ \\
\hline (i) & $\begin{array}{l}\text { Other } \\
\text { Predominantly* personalt communication? }\end{array}$ & $\begin{array}{l}3.92 \% \\
11.76 \%(6 / 51)\end{array}$ \\
\hline $\begin{array}{l}\text { (i) } \\
\text { (ii) }\end{array}$ & $\begin{array}{l}\text { Predominantly electronic communication? } \\
\text { Other }\end{array}$ & $\begin{array}{l}64.71 \%(33 / 51) \\
23.53 \%(12 / 51)\end{array}$ \\
\hline 8.3 & An entity for sharing information? & Yes: $95 \%(55 / 58)$ \\
\hline a & Area within England & $16.36 \%(9 / 55)$ \\
\hline b & Throughout England & $9.09 \%(5 / 55)$ \\
\hline c & Both & $67.27(37 / 55)$ \\
\hline (i) & $\begin{array}{l}\text { Other } \\
\text { Predominantly* personalt communication? }\end{array}$ & $\begin{array}{l}7.27 \%(4 / 55) \\
10.9(6 / 55)\end{array}$ \\
\hline $\begin{array}{l}\text { (i) } \\
\text { (ii) }\end{array}$ & $\begin{array}{l}\text { Predominantly electronic communication? } \\
\text { Other }\end{array}$ & $\begin{array}{l}63.64 \%(35 / 55) \\
25.45 \%(14 / 55)\end{array}$ \\
\hline 8.4 & An electronic database? & $72.41 \%(42 / 58)$ \\
\hline a & Area within England & $11.9 \%(5 / 42)$ \\
\hline b & Throughout England & $23.81 \%(10 / 42)$ \\
\hline c & $\begin{array}{l}\text { Both } \\
\text { Other }\end{array}$ & $\begin{array}{l}54.76 \%(23 / 42) \\
9.52 \%(4 / 42)\end{array}$ \\
\hline 8.5 & An entity for education of public health professionals & $70.69 \%(41 / 58)$ \\
\hline a & Area within England & $14.63 \%(6 / 41)$ \\
\hline b & Throughout England & $12.2 \%(5 / 41)$ \\
\hline \multirow[t]{2}{*}{ c } & Both & $65.85 \%(27 / 41)$ \\
\hline & Other & $7.31 \%(3 / 41)$ \\
\hline \multirow{3}{*}{$\begin{array}{l}\text { (i) } \\
\text { (ii) }\end{array}$} & Predominantly* personalt communication? & $39.02 \%(6 / 41)$ \\
\hline & Predominantly electronic communication? & $48.78 \%(20 / 41)$ \\
\hline & Other & $12.02 \%(5 / 41)$ \\
\hline 8.6 & Virtual team & $79.31 \%(46 / 58)$ \\
\hline
\end{tabular}

they were mentioned was calculated. A function or theme mentioned twice by the same person was only counted once. Question 9.7 gives the interviewees an option to mention any functions, not already mentioned which according to their understanding would be provided by a public health network. The themes identified from this were added to the results of question 8.

Analysis of question 10 requires analysis of the functions identified and of their ranking. The top four answers were given a score of between 4 (highest rank) to 1 (lowest rank) and then assigned to a function. The maximum total score for each question was 10,9, 7, or 4 depending on whether 4 (or more), 3, 2, or 1 answers (that is, functions) were listed. Answers, which were equally ranked by the interviewee, would have their scores split. For example, if the highest ranking were split between two answers, then each would get a score of 3.5. Each option in questions 12-14 had a score calculated with the highest score indicating that the option was frequently picked and/or had many high rankings. The scoring system is identical to that described for question 10 only that 5 is the highest score and the maximum score was
15. The total times an option was selected was also recorded. When the interviewees were indifferent to one of the options presented the answers were randomly allocated to either "yes" (but not ranked) or "no".

Minitab statistical software was used to test the hypothesis that a greater proportion of interviewees understood that people would spend more time communicating with each other electronically (that is, over intranet/internet) compared with personal communication (that is, by phone/meetings). The question was asked in relation to four of the six functions provided in question 9, giving a total of 224 questions. Sixty eight times the interviewee's response was included in the "other" category leaving a sampling number of 156 questions. An interviewee whose majority of answers (for eample, three of four questions) nominated electronic communication was included in the proportion who understood that member of the network would spend more time communicating with each other electronically than non-electronically. Those who nominated the same number of answers for electronic compared with non-electronic communication were assigned to neither proportion. 
Table 3 The results of question 8

\begin{tabular}{ll}
\hline Theme & Frequency of occurrence \\
\hline Network of public health professionals & 23 \\
Maximise scarce resources & $21\left(+5^{*}\right)$ \\
Sharing information/knowledge & $15\left(+2^{*}\right)$ \\
CPD/training/education & $11\left(+2^{*}\right)$ \\
Deliver public health work/function/agenda & $10\left(+1^{*}\right)$ \\
Knowledge management & $8\left(+2^{*}\right)$ \\
Improve efficiency/reduce duplication & 7 \\
Peer support/reduce isolation & $6\left(+7^{*}\right)$ \\
Network covering a geographical area & 6 \\
Work across organisational boundaries & 6 \\
Locate expertise & $5(+2)$ \\
Identify and link people with similar & $5(+1)$ \\
interests & 5 \\
Provide a means of communication & 5 \\
Work as a virtual team despite & \\
geographical distance & $3\left(+2^{*}\right)$ \\
Provide guidance in public health matters & \\
to its members & 3 \\
Coordination of multidisciplinary work & 3 \\
Work in partnership & 5 \\
Other &
\end{tabular}

\section{RESULTS}

Only two public health professionals, out of a total of 60 asked felt that they didn't have some understanding of the term "public health networks". The average public health professional was found to spend 25 hours/week (SD 10.7) using a computer and about $50 \%$ of that time is on the internet/intranet. Table 2 shows that according to their understanding the two functions that are most likely to be provided by a public health network, are linking public health professionals in a defined geographical area (98.3\%) and sharing information/skills (95\%).

The most common themes, functions, and comments mentioned in the interview are illustrated on tables 3 and 4. The less common ones can be found in appendix C (see journal web site www.jech.com/supplemental). Table 3 shows that in response to question 8 (which asks them to define their understanding of a public health network) the themes most commonly mentioned include a network for public health professionals (23) maximising scarce resources (21) and sharing of information (15). The average number of themes mentioned per person was 2.43 (SD 1.33) with considerable variation in the type of themes mentioned with only 10 interviewees mentioning the two most common.

Table 4 shows the results of question 10 (which asks which functions the user would most like to see the public health network provide). The commonest functions desired are:

- Identify expertise and maximise scarce resources-that is, coverage of public health organisations (for example, PCTs). This includes taking a lead by people/organisations in certain areas of public health (expertise or services).

- Continuing professionals development (CPD)/education/ training of those in public health

- Efficient information/knowledge management

By aggregating the most commonly identified functions and themes a consensus definition of a public health network was produced:

\begin{abstract}
"A network of public health professionals within a defined geographic area which facilitates communication, information sharing and linking of those with common interests/skills to enable efficient working across organisational boundaries to deliver the public health function".
\end{abstract}

The hypothesis that, according to their understanding, a greater proportion of public health professionals understood that communication would be predominantly electronic compared with personal communication (by phone/meetings) was accepted with $95 \%$ confidence intervals $(p=0.000)$. In the subanalysis of the 36 interviewees who understood that the public health network would provide an

Table 4 The results of question 10

\begin{tabular}{|c|c|c|}
\hline Function & $\begin{array}{l}\text { Number of times } \\
\text { mentioned }\end{array}$ & Score \\
\hline CPD/education/training & 35 & 65.2 \\
\hline Sharing of information/knowledge & 23 & 61.2 \\
\hline Sharing skills/expertise and maximise scarce resources & 20 & 55.2 \\
\hline Database of public health information and knowledge management & 21 & 55 \\
\hline Locate expertise & 18 & 49 \\
\hline Reduce duplication/improve efficiency & 14 & 35.2 \\
\hline Work as a virtual team despite geographical distance & 13 & 21.5 \\
\hline Peer support/reduce isolation & 8 & 19.7 \\
\hline Deliver public health work/function/agenda & 4 & 17 \\
\hline Best practice/standards & 9 & 17 \\
\hline Forum For dialogue without need to travel & 2 & 13 \\
\hline Keep up to date & 5 & 12 \\
\hline Develop and influence policies & 9 & 12 \\
\hline Coordination of multidisciplinary public health work & 6 & 11.5 \\
\hline $\begin{array}{l}\text { Information on what is happening elsewhere in other public health } \\
\text { organisations/groups }\end{array}$ & 5 & 11 \\
\hline Locate people & 4 & 10 \\
\hline Governance & 6 & 10 \\
\hline Arrange meetings & 2 & 8 \\
\hline Identify and link people with similar interests & 5 & 7.5 \\
\hline Provide guidance in public health matters to its members & 2 & 6.5 \\
\hline Provide a means of communication & 4 & 6 \\
\hline Information on meetings & 3 & 5 \\
\hline Preserve organisational memory & 3 & 3.7 \\
\hline Evidence based medicine & 3 & 3 \\
\hline Provide an identity for public health & 3 & 2 \\
\hline Pose questions to the network & 3 & 0 \\
\hline
\end{tabular}




\begin{tabular}{|llll|}
\hline \multicolumn{2}{l}{ Table 5A Web site options most commonly chosen } & & \\
\hline Option & $\begin{array}{l}\text { Number of times chosen } \\
\text { (out of 22) }\end{array}$ & $\begin{array}{l}\text { Number of times } \\
\text { in top five rank }\end{array}$ & Score \\
\hline Contact information & 22 & 21 & 87.1 \\
Areas of expertise & 21 & 19 & 58 \\
Job title & 22 & 12 & 35.6 \\
Location & 21 & 14 & 35.4 \\
Current projects & 21 & 13 & 28 \\
Areas of interest & 22 & 12 & 25 \\
Publications/reports/presentations & 15 & 8 & 13.4 \\
Titles & 4 & 3 & 3.4 \\
Summaries & 8 & 1 & 5 \\
Eull text & 3 & 7 & 12.2 \\
Educational history & 16 & 2 & 4.5 \\
Availability to work & 9 & 2 & 3.9 \\
Employment history & 10 & 3 & 1.9 \\
Links to public health web sites & 18 & 1 & 1.4 \\
Awards/distinction & 11 & 0 & 0 \\
Referees & 4 & 0 & 0 \\
Links to non-public health web sites & 8 & & \\
\hline & & & \\
\hline
\end{tabular}

educational function (question 9.5) 20 interviewees understood that communication would be mostly electronic and 16 felt it would be mostly by phone/meetings. When these two proportions were compared the difference was not statistically different $(\mathrm{p}=0.343)$.

Of the 22 people who were asked, 18 were in favour of a national network, three were indifferent, and one didn't know. Some $23.3 \%, 93.3 \%$, and $93.3 \%$ of interviewees were in favour of their own individual web site, a web site for their local network, and a web site for the national network respectively (questions 12-14). The commonest reasons for not wanting an individual web site include "don't see the value/benefits", "don't want to have to maintain it", and "don't want to update it". Other common reasons were that they would not like having such personal information widely available, they did not feel they were of sufficient interest to someone else to warrant a web site, and they don't like self promotion. The commonest reasons for not wanting a local web site include not seeing the value and because they "don't feel it's worth the effort/maintenance. Those not in favour of a national web site argue that they could not see its value and that they would prefer personal dissemination of information.

For individual web sites on the network and for the web sites supporting local and national networks tables 5A, B, and
C show the web site options that were most commonly chosen, the frequency with which they were in the top five ranking, and the overall scores in the ranking system. For individual web sites the three choices with the highest scores were contact information, areas of expertise, and job title. For local web sites the options, which scored the highest, were a search to locate expertise, current projects, and a search to locate a person in public health. For the national web site the highest scoring options were the search to locate expertise, current projects, and the search to locate reports.

Question 15 recorded any comments the interviewees made during or at the end of the interview. The commonest three comments mentioned can be paraphrased as follows:

- The public health network is not one network but rather a series of different networks (nine interviewees)

- With the current trend towards electronic communication face to face communication is essential for the success of public health networks (eight interviewees).

- Public health networks need to be managed.

Less common comments are mentioned in appendix C (see jounal web site www.jech.com/supplemental) and include the need to manage the huge number of emails, which public health professionals are receiving daily and the need to free

Table 5B Frequency with which web site options were in the top five ranking

\begin{tabular}{llll}
\hline Option & $\begin{array}{l}\text { Number of times } \\
\text { chosen (out of 56) }\end{array}$ & $\begin{array}{l}\text { Number of times } \\
\text { in top five rank }\end{array}$ & Score \\
\hline Search to locate expertise & 56 & 51 & 166.6 \\
Current projects & 55 & 32 & 123.6 \\
Search to locate person & 55 & 33 & 98.85 \\
Contact details for web site & 56 & 23 & 89.18 \\
Search to locate reports & 55 & 41 & 84.6 \\
About us & 55 & 19 & 71.1 \\
Links to public health web sites & 53 & 19 & 51.1 \\
Search to locate interest & 49 & 22 & 46.6 \\
Information on training courses/meetings & 54 & 18 & 41.3 \\
within the geographical area of the network & & & 39.15 \\
Mission statement & 39 & 11 & 31.1 \\
Search to locate publications & 36 & 14 & 23.6 \\
Search to locate presentations & 49 & 12 & 11.89 \\
Information on health organisations within the & 45 & 6 & \\
geographical area of the network & & & \\
\hline
\end{tabular}




\begin{tabular}{|llll|}
\hline \multicolumn{2}{|l|}{ Table 5C Overall scores in the ranking system } & & \\
\hline Option & $\begin{array}{l}\text { Number of times chosen } \\
\text { (out of 56) }\end{array}$ & $\begin{array}{l}\text { Number of times in } \\
\text { top five rank }\end{array}$ & Score \\
\hline Search to locate expertise & 56 & 47 & 152.6 \\
Current projects & 54 & 29 & 102.17 \\
Search to locate reports & 53 & 32 & 87.74 \\
Search to locate person & 56 & 30 & 86.35 \\
Contact details for network & 56 & 20 & 69.21 \\
About us & 52 & 19 & 65.92 \\
Links to public health web sites & 52 & 21 & 52.99 \\
Search to locate interest & 49 & 23 & 50.24 \\
Online training/education & 51 & 20 & 49.63 \\
Mission statement & 39 & 13 & 47.3 \\
Information on training courses/meetings / & 55 & 19 & 45.03 \\
conferences within the network & 45 & 20 & 39.24 \\
Search to locate publications & 49 & 10 & 18.74 \\
Search to locate presentations & 49 & & \\
\hline
\end{tabular}

up more time for senior public health professionals to contribute to the public health network.

\section{DISCUSSION}

This study has defined a consensus understanding of the term "public health network" and defined what functions public health professionals want the network to provide. In addition we have also explored the support for a national network and for web sites and their user requirements at an individual, local, and national network level.

We found that within England public health professionals understanding of the term "public health network" varies considerably from person to person. The consensus understanding of public health networks is similar but broader than that of the government (as defined in STBoP) $)^{12}$ but with greater emphasis on information and knowledge sharing. Both public health professionals and the government define the public health network(s) by geographical areas although STBoP states that they are defined by the boundaries of the strategic health authority whereas those interviewed in this study saw them being defined both locally and nationally. In reality the different networks commonly exist at a borough, strategic health authority, regional, national, and even international levels. Some of this geography is defined by the organisation that coordinates the network, for example, West Midlands public health observatory network. ${ }^{6}$ Many interviewees also felt that although the network(s) is/are defined by geography that it/they is/are also defined by common interests/skills.

In their comments many interviewees felt that there isn't one public health network but rather there are many different networks with different roles and functions. Yet one could also say that there is only one public health network, which consists of many different sub-networks,

\section{Policy implications}

- The United Kingdom public health network is more likely to be successful if its priorities are maximising scarce resources, identification of expertise, CPD/ education, and knowledge management as these are the functions that are desired by most public health professionals and supported by the government.

- A national public health network should be created to advise on standards that its sub-networks would agree to adhere to ensure interoperability and thus better knowledge management. which may have different functions, responsibilities, and degrees of formality.

Because resources for these networks are dependent on government support one needs to identify, which are the desired functions, which are in keeping with the government's plans. Therefore the main priority for these networks should be the maximisation of scare resources, identification of expertise, $\mathrm{CPD} /$ education, and knowledge management as these are clearly very popular functions with the government and with public health professionals. One interesting distinctions in priority was sharing good practice, which was in the top four government functions whereas it ranked 10th in the desired functions of public health professionals. This may reflect the need for the government to have standard practice and avoid the bad publicity from inequalities in service as compared with the need of public health professionals to have local autonomy. Also, in their description of public health networks the FPHM ${ }^{3}$ emphasised that their work would be performance managed but this was only a desired function in six of the interviewees. This may reflect the desire of the individual public health professional to have an open and unconstrained network as compared with the organisation's desire to have it controlled and performance managed.

Given the scenario where there is a national network and a series of local networks there is clearly a good deal of support in favour of web sites for these networks. The most desired features include a search to identify expertise, a search to locate a public health person, a search to locate reports and information about current projects of those in the network. These needs probably reflect the desire to tackle the isolation of public health professional who have difficulty finding people after the latest re-organisation and the desire to identify reports that are rarely catalogued and therefore end up lost in a file in the bottom drawer of an old health authority. The least popular features include mission statements, which could reflect the dislike of too much formality in a network. Other unpopular features include locating publications, which probably reflects the desire to avoid replication as this function is available elsewhere.

Most of those asked were not in favour of individual web sites. The most popular reason given was that they could not see the value/justification. Yet individual web sites are useful because they provide a snapshot of ourselves, what we are doing, and what are our skills. They would avoid the need for this information to be kept on many different databases because the database would just keep a link to the web site whenever the person's name is mentioned (for example, in a publication or as an identified expert.) The $23 \%$ of interviewees who were in favour of individual web sites 
were keen to have information about how they could be contacted and their areas of expertise but clearly there were objections to self marketing as features such as awards/ distinction, referees, and their contact details were very unpopular. To improve their popularity one needs to demonstrate their usefulness and overcome certain cultural barriers such as society frowning upon self promotion or marketing. Breaking these barriers is essential because the public health message needs to be sold therefore public health professionals need to sell themselves.

This study has shown that most public health professionals understand that most of the time spent communicating on these networks will be electronic however the importance of combining this with regular face to face meetings was emphasised by many interviewees. There is also a desire and an understanding that the public health network will consist of different groups of people who will create virtual teams in which they are using predominantly electronic means to communicate and perform public health work. These observations highlight the need to allocate time in a public health professional's week to devote to the public health network and the need to train public health professionals in the use of information technology and techniques of computer mediated communication. A study by Warkentin and Beranek ${ }^{7}$ showed that the quality of work produced by virtual teams, was better in those with training in computer mediated communication.

The need and desire for knowledge management is clear from this study. Seventy two per cent of public health professionals understood that the public health network would provide a database of public health information/ knowledge. For this to be successful there needs to be a culture of sharing and goodwill between public health professionals/organisations and resources (for example, databases) being made available to manage the information. Also, agreeing common standards on information structure, coding, tagging, communication, and storage is vital to improve interoperability thus permitting powerful and meaningful searching across all the public health databases. Without common standards we will either have meaningless or no communication between different databases. One approach is for all public health professionals to use common labels to identify our documents and these labels would have the same meaning for everybody. Such a tagging standard has been developed by the Eastern Region public health observatory. ${ }^{8}$.

Eighty two per cent of those asked were in favour of a national network. We do not see a national network as a body to oversee the local networks but rather as one whose main role would be to facilitate essential functions such as suggesting common standards to ensure interoperability between networks. Prototype web sites, which demonstrate how the local public health network would interact with a national public health network, were developed ${ }^{10}$ in response to the results of the study and are available to view (http:// www.pubnetuk.wtcsites.com/index.html).

\section{LIMITATIONS}

Samples were taken from the north, east, west, and south of England although most interviewees were from Oxfordshire, Ealing, and Westminster primary care trusts. Ideally the sample would have been larger with exactly the same number of people from different regions around England, with equal numbers from rural and urban settings, from the different organisations, and from different job titles. The interviews however were at a time when the changes of $\mathrm{STBOP}^{12}$ were being implemented and many public health professionals were changing jobs. The advantage of this is that the study was performed at a time when most networks were not well developed but public health professionals were particularly concerned about isolation and thus recognised the need for public health networks. Its disadvantage was that arranging interviews was difficult and the interviewees were a "moving target".

The results of the interview are somewhat limited by the number of closed questions. This reduces the scope of the responses. However, we felt that we would have lost the interest of the interviewees if more questions were open thus prolonging the length of the interview.

\section{CONCLUSION}

This study has three main conclusions. Firstly, we conclude that there are similarities between public health professionals understanding of the term public health networks and that of the governments but that public health professionals have a broader understanding with more emphasis on sharing information/knowledge. Secondly, the public health network is more likely to be successful if its priorities are maximising scarce resources, identification of expertise, CPD/education and knowledge management as these are the functions that are desired by most public health professionals and supported by the government. Thirdly, there is considerable support for a national public health network and for public health web sites to represent local and national networks. These web sites should provide information on current projects of the network and searches to identify people, expertise, and reports.

\section{ACKNOWLEDGEMENTS}

We would like to acknowledge the support and help from the National Electronic Library for Health, the MIM Centre, City University, London and the Institute of Health Sciences in Oxford.

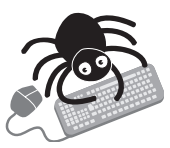

The appendices are available to view on the journal web site (http://www.jech.com/supplemental).

\section{Authors' affiliations}

D K Fahey, E R Carson, D G Cramp, City University, London, UK

J A Muir Gray, Institute of Health Sciences, Oxford, UK

\section{REFERENCES}

1 STBoP. Shifting the balance of power: securing delivery. 2002. http:// www.doh.gov.uk/shiftingthebalance/initialconsult.htm (accessed 17 Jan 2003).

2 STBoP. Shifting the balance of power: the next steps. 2001. http:// www.doh.gov.uk/shiftingthebalance/nextsteps5.htm\#appc (accessed 17 Jan 2003).

3 FPHM. Developing public health in primary care trusts-a framework for discussion (appendix 1). 2001. http://www.fphm.org.uk/Policy/ Developing\%20Public\%20Health\%20in\%20Primary\%20Care\%20Trusts.doc (accessed 19 Jan 2003).

4 Wessex regional health authority. Regional information systems plan. Case facts. http://www.scit.wlv.ac.uk/ cm 1995/cbr/cases/case04/13. HTM (accessed 20 Mar 2003).

5 Oppenheim AN. Data processing. In: Questionnaire design, interviewing and attitude measurement. 1st edn. London: Continuum, 1992:262-3.

6 Association of public health observatories. http://www.wmpho.org.uk/ directory (accessed 30 Sep 2003).

7 Warkentin M, Beranek P. Training to improve virtual team communication. Information Systems Journal 1999;9:271-89.

8 Eastern region public health observatory. http://www.erpho.org.uk (accessed 20 Mar 2003).

9 Public health information tagging standard. http://www.phits.org.uk (accessed 20 Mar 2003).

10 Fahey DK. Public health networks: a systemic and model based approach, [MSc thesis]. London: City University, 2002. 